\title{
Comparison of Yoga vs. Relaxation on Chemotherapy Induced Nausea and Vomiting Outcomes: A Randomized Controlled Trial
}

Malur R Usharani ${ }^{1}$, PKL Nandini ${ }^{2}$, Raghavendra Rao M $^{1 *}$, Mahesh Kavya ${ }^{1}$, S Aishvarrya ${ }^{1}$, Shekhar G Patil ${ }^{1}$, Diwakar B Ravi ${ }^{1}$, H P Shashidhara ${ }^{1}$, C T Satheesh ${ }^{1}$, Naik Radheshyam ${ }^{1}$, Basavalinga S Ajaikumar ${ }^{1}$, Gopinath $\mathrm{KS}^{1}$ and Ramesh BS

${ }^{1}$ Health Care Global Enterprises Ltd, Centre for academic research HCG Foundation Bangalore

${ }^{2}$ Swami Vivekananda Yoga Anusandhana Samsthana, Svyasa University, Bangalore

"Corresponding author: Raghavendra Rao Mohan, Centre for academic research HCG Foundation, No 8, P Kalinga Rao Road, Sampangiramnagar, Karnataka-560027, India, Tel: +91-08040206309; E-mail: raghav.hcgrf@gmail.com

Rec date: Aug 9, 2013, Acc date: May15, 2014, Pub date: June 5, 2014

Copyright: (c) 2014 Usharani RM, et al. This is an open-access article distributed under the terms of the Creative Commons Attribution License, which permits unrestricted use, distribution, and reproduction in any medium, provided the original

author and source are credited.

\section{Abstract}

Objective: Nausea and emesis are two major side effects and known to be partly psychological rather than purely pharmacological in nature. Yoga as a complimentary modality is extensively known to reduce anxiety, physiological arousal and stress associated with chemotherapy. This study will compare the effect of Yoga with Jacobson's relaxation to understand the underlying neural mechanisms like gastric motility changes (Electrogastrogram) and sympathovagal changes on HRV spectral analysis that accompany chemotherapy induced nausea and emesis and evaluate the influence of intervention on these mechanisms.

Method/Design: This is a randomized controlled 3 arm clinical Trial. 120 chemo naive subjects will be randomized into three groups, with 42 subjects for Yoga, 42 for Jacobson's group and 36 in control group.

Setting: This study will be conducted at Comprehensive cancer care hospital.

Participants: 200 patients will be screened and 150 subjects who satisfy the selection criteria (those with gynecological malignancies, between 18-70 years, with basic education and those who have never been exposed to chemotherapy before and who give their consent to participate and give consent to participate) will be taken into the study.

Primary outcome measure: The Functional Living Index-Emesis (FLIE), emesis-and nausea-specific Qol questionnaire is administered with a 24 hour recall followed by a 4-day recall for studying acute and delayed chemotherapy-induced emesis.

Secondary outcome measure: Include psychological measures such anxiety, depression and perceived stress that influence chemotherapy induced nausea and emesis. It also includes cardiac autonomic function and surface electrogastrogram to assess the neurophysiological correlates of yoga in modulating nausea and emesis.

Intervention: The yoga intervention consists of asanas (postures), breathing exercises, and relaxation techniques for 25 minutes. The progressive muscle relaxation involves tightening each and every muscle of the body and then relaxing the same one by one for 25 minutes.

Conclusion: This study will help us understand the mechanism of action of yoga intervention in controlling chemotherapy induced nausea and vomiting.

\section{Key words:}

Nausea; Emesis; Yoga; Psychological stress; HRV; EGG

\section{Introduction}

Despite recent advances in the understanding of chemotherapy induced nausea and emesis and development of new generation antiemetic agents, nausea and emesis continue to be the most feared distressing side effect of chemotherapy [1]. The occurrence of nausea and emesis relative to chemotherapy administration can be classified as either acute (within first $24 \mathrm{hrs}$ with a peak of 5-6 hours), delayed (after 24 hours of administration) or anticipatory (nausea and emesis prior to subsequent doses of chemotherapy) [2]. Breakthrough CINV describes the onset of CINV despite the use of CINV prophylaxis and requires active use of antiemetic therapy. Recent studies have also reported that the incidence of nausea may actually have risen despite the reduction in the incidence of vomiting after the introduction of 5HT3 receptor antagonists [3]. This is further corroborated by two meta-analyses of clinical trials that have shown that 5-HT3 receptor antagonists being not effective against delayed emesis and nausea [4-6]. 
Citation: Malur R Usharani, PKL Nandini, Raghavendra Rao M, Mahesh Kavya, S Aishvarrya, et al. (2014) Comparison of Yoga vs. Relaxation on Chemotherapy Induced Nausea and Vomiting Outcomes: A Randomized Controlled Trial. J Integr Oncol 3: 116. doi: $10.4172 / 2329-6771.1000116$

Page 2 of 8

This inadequacy in CINV control stems from the fact that antiemetic regimens are tailored to manage acute emesis only and not delayed emesis and nausea $[7,8]$. The management and mechanism of delayed CINV is poorly understood and is largely based on empiric results. CINV can also cause physiological impairment, loss of functional ability and a decline in performance status $[6,9]$. When CINV is severe, it may lead to a clinical decision to cease chemotherapy or reduce dose or patients may even withdraw from further cycles of planned chemotherapy [6]. It has been reported that dose reduction due to toxicity has led to poorer survival when chemotherapy was given for a curative intent [10-12]. In addition to affecting quality of life and clinical outcomes CINV makes a significant burden on health care resources [4,5].

Therefore, the cornerstone of effective CINV management is prophylaxis i.e preventing the first symptoms of CINV after chemotherapy administration. Various guidelines the Multinational Association of Supportive Care in Cancer (MASCC) and National Cancer Care Network (NCCN) propose the use of 5HT3 receptor antagonists and NK1 receptor antagonists along with corticosteroids [13]. However these guidelines are not followed in practice among the majority, there is lack of awareness of these guidelines and underestimation of incidence of delayed nausea and emesis by both physicians and nurses contributing to increase in prevalence of CINV [4]. Secondly, there is increased variability among patients on predisposition to CINV with same emetogenic potential due to several modifiable and non-modifiable host factors that increase risk for CINV [14]. Despite following guidelines $50 \%$ of patients still experience delayed nausea [15]. This is partly because of variable excitation and depression of several peripheral and central pathways and centers that take part in delayed gastric emptying following chemotherapy. Action on one or more of these sites can mitigate the problem.

While 5HT3 receptor antagonists act via peripheral mechanisms and NK1 receptor antagonists via central mechanisms in controlling acute nausea and emesis, substance $\mathrm{P}$ dependant central mechanisms have been purported to be behind occurrence of delayed nausea. These neurotransmitters have also been implicated in affective states such as anxiety and depression and their antagonists have shown to reduce these states subsequently $[16,17]$. Substance P levels have been shown to be reduced by moderate exercise in animal models [18]. This, coupled with the limitations imposed by use of pharmacologic therapy in managing CINV has helped encourage use of non-pharmacological means in managing CINV. The rationale for this study is therefore to see if stress reduction approaches alone or stress reduction with moderate exercise effect would help reduce delayed nausea and emesis.

There are two mechanisms by which this can happen i) stress reduction can help reduce the sensitivity of chemoreceptor trigger zone to afferent stimuli and ii) improving gastric motility can help reduce delayed gastric emptying following administration of chemotherapy and antiemetic agents. We therefore compared yoga with standard stress reduction approaches such as Jacobson's progressive muscle relaxation that has shown benefit finding in managing chemotherapy induced nausea and emesis [19]. Third, antiemetic agents induce gastroparesis that can contribute to delayed nausea which is a justifiable reason for using yoga to tone abdominal muscles and restore normal gastric motility as demonstrated in an earlier study on IBS patients [20]. Most of the antiemetic agents have no effect on gastric motor function and some may delay gastric emptying exacerbating nausea [21]. As a consequence management of chemotherapy induced nausea and vomiting is a common problem and most frequent cause of distress.

Furthermore anticipatory symptoms are caused by anxiety that is known to affect basal ANS tone [22] that exacerbates response to conditioned stimuli in these subjects. This also said to be mediated by the above mentioned neuropeptides. Therefore, these strong relationships between psychosocial variables, autonomic dysfunction and NV justify the need for integrating mind body therapies with pharmacological interventions in managing treatment related $\mathrm{NV}$ [23].

Yoga is one such mind body intervention that has been used in numerous health care concerns where stress is believed to play a role. It has both exercised and stress reduction effect. Our earlier studies, yoga on cancer patients have shown to reduce psychological distress [24], quality of life [25], anxiety [26], depressive symptoms, modulate salivary cortisol rhythms [25], improve sleep [27], and nausea and emesis [28]. This has been corroborated by other studies in a recent metaanalysis [29-31].

In this study we will study the mechanism of action of yoga intervention in modulating CINV. We are evaluating heart rate variability and cardiac autonomic function (deep breathing test, valsalva manoeuvre, diastolic blood pressure response following hand grip) to assess the sympathovagal balance which is a reliable marker of stress response in these individuals. We will also assess perceived stress, self-reported anxiety and depression that have shown to be reduced following yoga intervention to correlate with changes with heart rate variability and gastric motility. One of the important justifications for using yoga was to manage gastroparesis/delayed gastric emptying induced by antiemetics by its effect on gastric motility and reduce psychological stress both of which are known to modulate CINV. In this randomized controlled 3 arm study we chose to have progressive muscle relaxation as a control arm as it's primarily a stress reduction intervention that has shown benefits in managing CINV. We wanted to study whether yoga with antiemetic therapy is more beneficial in managing CINV than PMR with antiemetic therapy or antiemetic therapy alone.

\section{Research Design and Methods}

\section{Aims}

To conduct a randomized controlled clinical trial to evaluate whether:

1. Yoga intervention is superior to Jacobson's relaxation/ Progressive Muscle Relaxation (PMR) on CINV outcomes in chemotherapy naive cancer subjects.

2. Yoga intervention is effective in improving quality of life and reducing anxiety states.

3. Yoga has an influence on gastric motility changes (Electrogastrogram) and sympathovagal changes on HRV spectral analyses that accompany CINV.

\section{Hypothesis}

Yoga intervention will lead to greater decrease in NV outcomes following chemotherapy than PMR or only conventional treatment with antiemetic support. 
Citation: Malur R Usharani, PKL Nandini, Raghavendra Rao M, Mahesh Kavya, S Aishvarrya, et al. (2014) Comparison of Yoga vs. Relaxation on Chemotherapy Induced Nausea and Vomiting Outcomes: A Randomized Controlled Trial. J Integr Oncol 3: 116. doi: $10.4172 / 2329-6771.1000116$

Page 3 of 8

Yoga will also have an impact on gastric motility and sympathovagal balance on heart rate variability that accompany CINV.

\section{Methodology}

\section{Study Design}

This is a randomized controlled 3 arm clinical trial.

\section{Study Population}

Screening: Considering a lower prevalence of chemotherapy induced nausea and vomiting as $48 \%$, we will have to screen 416 participants to get 200 patients. Considering a refusal rate of $25 \%$ we would have 150 subjects for recruitment. These subjects will then be randomized into three groups' viz. yoga plus antiemetics (Group 1), PMR plus antiemetics (Group 2) and antiemetics only (Group 3), with 50 subjects in each group. We will choose to have 30 breast cancer patients, $10 \mathrm{Ca}$ Ovary and 10 Lymphoma patients in each group. Considering a dropout rate of $20 \%$, we will need a minimum thirty six evaluable subjects in each arm to complete the study.

\section{Recruitment}

Patients who meet the selection criteria will be referred by medical oncologists for the study. Prospective subjects are requested to give written consent if they agree to participate in the study. They will be then randomized into three groups to receive either yoga with antiemetic support, PMR with antiemetic support or antiemetic support only, before they receive their first cycle of chemotherapy. HRV recording and surface electrogastrogram will be recorded in a quiet room. A detailed clinical history with respect to motion sickness, hyper emesis during pregnancy and baseline questionnaire which include mood states, perceived stress, and quality of life will be abstracted. Then, the patient will be taken to a well-ventilated room where a session of practice is taught based on the group they are allotted. The patients will later receive their chemotherapy.

\section{Randomization}

Subjects will be randomized into any of the three groups using envelopes with group assignments. Random numbers will be generated using software for 3 group assignment (www.randomizer.org). Opaque Envelopes will be placed in the order of assignment and numbered. This will be done at the study start so that field personnel will not be able to change the order of assignments later.

\section{Power Calculation and Sample size}

Considering the standardized effect size with yoga intervention vs. supportive therapy as 0.69 for nausea frequency and 0.95 for nausea intensity based on findings from our earlier study [28] we chose the average estimate of the two $d=0.82$. The sample size needed in our study was based on formula; $\mathrm{n}=$ number of groups $/ \mathrm{d} 2 \mathrm{x} \mathrm{C}$, power, where, $d$ is the standardized difference and $C p$, power is a constant defined by values chosen for $\mathrm{p}$ value and power $[32,33]$. Considering $\mathrm{p}$ at 0.05 and $80 \%$ power, the $\mathrm{C}$ p, power value is 7.9 . Going by the formula we have $\mathrm{n}=3 / 0.822 \times 7.9=36$ subjects in each arm. Taking into consideration a dropout of $10 \%$ (4 subjects) we will recruit approximately 40 subjects in each arm.

\section{Selection Criteria}

\section{Inclusion criteria}

Patients with gynecologic malignancies breast, ovary, head and neck and Lymphomas aged between 18-70 years, with basic (high school) education and know to read and write English, who have never been exposed to chemotherapy before, and who give their consent to participate are enrolled for the study.

\section{Exclusion criteria}

1. Patients will be excluded if,

They have brain, spinal cord or GI primaries/metastases

Peritoneal fluid, uraemia, GI obstruction

Neurological disorders such as Parkinson's disease, myotonic dystrophy, uncontrolled diabetes and hypertension

Concurring medical condition likely to influence survival

Those who have been regularly participating in a behavioral intervention/yoga program for past six months.

1. Those with ECOG performance status more than 2 .

Justification: Gynecological malignancies and lymphomas are most common type of cancers and it will be easy to procure in large number and have good prognosis (at least for the study period).We have restricted the age limit to 70 years since HRV will be interfered in older age group. Subject should have completed their high school so that, they will be able to understand and follow the intervention taught and co-operate to answer the psychological assessments included in the study.

Patients will be excluded if they have brain or GI metastases, peritoneal fluid, uremia, GI obstruction, (as they could exacerbate symptoms of NV); neurological disorders such as Parkinson's disease, myotonic dystrophy (as they could interfere with autonomic function test). Similarly, any concurring medical condition likely to influence survival, uncontrolled diabetes and hypertension, those who have pre conceived notions about yoga and have been regularly participating in a behavioral intervention/ yoga past six months.

\section{Assessment of outcomes}

\section{Primary outcome measures}

Involve measures for NV using FLIE and Nausea diary.

\section{Functional living index Emesis (FLIE)}

FLIE, a quality of life questionnaire specific to NV was originally developed and validated with a 3 -day recall period that covered the acute phase ( 24 hours post-chemotherapy) and the first 2 days of the delayed phase of CINV. In this study we use FLIE during the acute phase ( 24 hours post-chemotherapy with $24 \mathrm{hr}$ recall) delayed phase (days 2-6 post-chemotherapy with 4 day recall). This has been validated in earlier studies and has shown excellent internal consistency and reliability within the FLIE- NV domains (Cronbach's alpha range: 0.75 to 0.78). FLIE emesis-and nausea-specific Qol questionnaire administered with a 24 hour recall followed by a 4 -day recall has adequate measurement characteristics for studying acute and delayed CINV [34]. 
Citation: Malur R Usharani, PKL Nandini, Raghavendra Rao M, Mahesh Kavya, S Aishvarrya, et al. (2014) Comparison of Yoga vs. Relaxation on Chemotherapy Induced Nausea and Vomiting Outcomes: A Randomized Controlled Trial. J Integr Oncol 3: 116. doi: $10.4172 / 2329-6771.1000116$

Page 4 of 8

\section{Secondary outcomes}

It includes Psychological measures such as anxiety, depression and perceived stress. It also includes cardiac autonomic function and surface electrogastrogram to assess the neurophysiological correlates of yoga in modulating NV (Table 1).

\begin{tabular}{|c|c|c|c|c|}
\hline Measures & $\begin{array}{l}\text { Prior to } 1 \mathrm{st} \\
\text { cycle } \\
\text { Baseline }\end{array}$ & $\begin{array}{l}7 \text { th day of } 1 \text { st } \\
\text { cycle }\end{array}$ & $\begin{array}{l}\text { 2nd } \\
\text { cycle }\end{array}$ & $\begin{array}{l}\text { 4th } \\
\text { cycle }\end{array}$ \\
\hline \multicolumn{5}{|l|}{ Baseline data } \\
\hline $\begin{array}{l}\text { Socio demographic and } \\
\text { clinical characteristics }\end{array}$ & * & & & \\
\hline \multicolumn{5}{|l|}{ Questionnaire } \\
\hline $\begin{array}{l}\text { Functional living index } \\
\text { emesis }\end{array}$ & & * & & * \\
\hline Nausea and emesis diary & * & * & * & \\
\hline $\begin{array}{l}\text { Hospital anxiety and } \\
\text { depression scale }\end{array}$ & * & & & * \\
\hline $\begin{array}{l}\text { STAI - Spielbergers State } \\
\text { trait anxiety inventory }\end{array}$ & * & * & * & * \\
\hline Perceived stress scale & * & & & * \\
\hline \multicolumn{5}{|l|}{$\begin{array}{l}\text { Intervention } \quad \text { related } \\
\text { information }\end{array}$} \\
\hline Adverse experiences & * & * & * & \\
\hline $\begin{array}{l}\text { Adherence to practice along } \\
\text { with home practice }\end{array}$ & * & * & * & \\
\hline $\begin{array}{l}\text { Perception about Yoga and } \\
\text { Jacobson's exercise }\end{array}$ & * & * & * & \\
\hline Reasons for not practicing & * & * & * & \\
\hline \multicolumn{5}{|l|}{ Potential confounders } \\
\hline $\begin{array}{l}\text { Practicing: other type of } \\
\text { relaxation techniques/ yoga } \\
\text { practices }\end{array}$ & * & * & * & \\
\hline $\begin{array}{l}\text { Use of any other alternative } \\
\text { medicine }\end{array}$ & * & * & * & \\
\hline \multicolumn{5}{|l|}{ Neural Mechanism } \\
\hline HRV analysis & * & * & * & * \\
\hline Electrogastrogram & * & * & * & * \\
\hline
\end{tabular}

Table 1: Assessments of Outcome and Intervals

\section{Psychological Assessments}

\section{Spielberger's State Trait Anxiety Inventory (STAI - State scale)}

It consists of separate self-report scale for measuring two distinct anxiety concepts-state anxiety and trait anxiety [21]. These scales have twenty statements each with a concurrent validity ranging from 0.75 to 0.80 with other tests. The A-state scale asks the subjects to indicate how they feel at a particular moment in time. Subjects are asked to rate on a 4 point scale (almost never/not at all to almost always/very much) whether or not each statement best describes their feelings. Because the state measure is regarded similar to mood measures that have expectedly low test - retest reliability's, comparison of internal consistencies between the state and trait measure is more appropriate. Coefficient alpha reliabilities for the state measure range from 0.86 to $0.92[20]$.

\section{Perceived stress Scale (PSS)}

The PSS is a ten-question scale commonly used to measure perceived stress or the level at which individuals view their current life situations as stressful. The reliability of the PSS has been determined from both estimates of internal consistency and test-retest correlations. Reliability (internal reliability) of the PSS instrument is very strong, ranging from 0.84 to 0.86 , and validity ranging from 0.31 to 0.76 , when correlated with measures of physical and depressive symptoms. Estimates of internal consistency among psychiatric outpatients $(0.80)$ and in the general population $(0.75)$ have also been within acceptable limits [27,35].

\section{Hospital Anxiety and Depression Scale (HADS)}

HADS questionnaire measure participants self-report anxiety [36]. This scale has seven questions each to measure anxiety and depression. This scale has been developed to detect anxiety and depression in medically ill populations and has a strong reliability and validity with other scales and DSM III criteria. The reliability of HADS -A scale ranges from 0.63 to 0.90 across studies [37].

\section{Assessment of Neural mechanism}

\section{Cardiac autonomic function (ECG)}

The basal cardiac autonomic status will be evaluated using HRV which gives us a measure of sympathetic or parasympathetic dominance before and after a water load test. The ECG will be recorded for $5 \mathrm{~min}$ before water intake and $10 \mathrm{~min}$ after using $\mathrm{Ag} /$ $\mathrm{AgCl}$ solid adhesive pre-gelled electrodes (Biopac). The ECG will be acquired using an ambulatory ECG system (Biopac) at a sampling rate of $1024 \mathrm{~Hz}$ and will be stored for off line analysis. The $\mathrm{R}$ wave will be detected to obtain a point event series of successive R-R intervals, from which the beat to beat heart series will be computed. The data will be analyzed with an advanced HRV analysis software program inbuilt in the system. Apart from HRV we will also assess cardiac autonomic function by using a deep breathing test, isometric hand grip and valsalva manuevre which would give us a better picture of cardiac autonomic function and sympathovagal balance.

\section{Gastric autonomic function using surface electrogastrogram (EGG)}

Surface EGG will be assessed using a AD Instruments polygraph with EGG amplifier using three $\mathrm{AgCl}$ electrodes. In humans the normal frequency is (2.75- 3.75) or 3 cycles per minute (cpm). Bradygastria is an abnormally low frequency $(1.0-2.75 \mathrm{cpm})$ and tachygastria is abnormally high frequency $(3.75-10.0 \mathrm{cpm})$. This test is recorded for 15 minutes in fasting and thirty minutes after a $250 \mathrm{ml}$ water load test. Water load is preferred as a provocative test because comparable results can be achieved in less time ( 30 minutes vs. 2 hours) and the effects of secretin, cholecystokinin and hormonal responses are limited due to lack of calories in the test meal. Water load also avoids stimulating colonic neuromuscular activity while still 
Citation: Malur R Usharani, PKL Nandini, Raghavendra Rao M, Mahesh Kavya, S Aishvarrya, et al. (2014) Comparison of Yoga vs. Relaxation on Chemotherapy Induced Nausea and Vomiting Outcomes: A Randomized Controlled Trial. J Integr Oncol 3: 116. doi: $10.4172 / 2329-6771.1000116$

Page 5 of 8

provoking symptoms such as bloating and nausea [38,39]. Bradygastria can be a result of delayed gastric emptying caused due to antiemetics and any reduction in bradygastria would infer better gastric motility.

EGG rhythm disturbances have been seen in patients reporting nausea in the first trimester of pregnancy. In addition to this, many patients with unexplained NV exhibit slow wave disturbances. While some of them exhibit abnormalities with delayed gastric emptying, most of them exhibit EGG dysrhythmias or abnormal amplitude responses to meal ingestion $[9,40,41]$.

\section{Assessment intervals}

We will collect data on socio demographic characteristics, psychological, physical and physiological factors related to NV. We will take the data which includes psychological assessments at baseline (Cycle one), 7th day of first cycle to observe whether the intervention had any effect on delayed NV. Hence we will take the HRV and EGG recording on 7th day. We will also assess at second and fourth cycle of chemotherapy to see whether the intervention had any long term effect on CINV. This will help us understand the cardiac autonomic function and gastric motility changes with respect to acute as well as delayed emesis and understand if there are any adaptations or worsening over time and several chemotherapy cycles. We will also be able to ascertain the time for normalization of gastric motility and sympathovagal balance with Yoga / Jacobson's intervention.

\section{Intervention}

The subjects will be randomized to receive any of the three interventions. Patients in all three groups will receive antiemetic therapy as per the current [42], ASCO guidelines [43] during their course of chemotherapy. However, we will consider receiving moderately emetogenic chemotherapy.

\section{Masking}

It is not possible to mask yoga intervention from study participants as Indian population are sensitized to yoga postures and the very knowledge of the names of yoga posture prevents us from blinding participants to yoga intervention. However the HRV assessments and EGG recordings were masked from investigators (Neurophysiologists) who were blind to allocation.

\section{Yoga and anti-emetic group}

We have developed an integrated yoga program that uses a combination of asanas or postures (sitting, lying down and prone postures) and yogic relaxation techniques. We have selected postures which primararily tone abdominal muscles are simple, easy to learn, remember and perform without much discomfort as the basis of our intervention. All the practices are designed in such a way that they relax abdominal region and calm down the mind which might help reduce muscular contractions in the gastrointestinal tract [20] that accompany post CINV or may decrease the sensitivity of chemoreceptor trigger zone to vomiting response (stimuli) $[44,45]$. The participants will be asked to perform the practice on a yoga mat on the floor or on the bed. They will be asked to practice $2 \mathrm{hrs}$ after a meal or on empty stomach after evacuating their bowels and bladder. During practice they will be trained to be internally aware of the sensations and movements of their body. They will be asked to stop the practice if they felt uncomfortable.
As per yoga texts chemotherapy induced nausea and vomiting is as a result of sluggish flow of down ward life force called apana vayu due to aniemetic therapy resulting in derangement in the digestive fire called Samana vayu. Using supine lying down postures with Uttanapadasana (Extended stretch foot pose), pavanamuktasana (Wind relieving pose) prone such as bhujangasana (Cobra pose), makarasana (Crocodile pose). We will help restore the downward flow of apana vayu which translates to earlier gastric emptying thereby reducing symptoms of nausea and vomiting, [46]. These asanas have prokinetic action that acts on the gastric musculature to relieve symptoms. Secondly, we have used cooling pranayama called Shitali and sheetakari pranayama which involves swallowing air through mouth and exhalation through nostrils [46]. This is known to distend the abdomen and stimulate gastric emptying. These practices are then followed by yogic relaxation technique with breath awareness that has been shown to reduce stress in healthy practitioners [47].

\section{Anti-emetic and Jacobson's relaxation (PMRT) technique}

PMRT is a simple and systematic process of muscle relaxation with awareness and involves the alternation of tensing muscles and relaxing the sixteen major groups of muscles for ten counts.

The duration for both the interventions are same where the participants practice for 25 minutes and continue to practice twice a day till fourth cycle of chemotherapy. Review will be done during every consecutive cycle to monitor the regularity in their practice. Phone calls are made to ensure they practice regularly.

Two separate DVDs containing demonstration and precautions for Yoga practices and Jacobson's relaxation technique will be given to participants. Initially participants will be taught by a certified and trained yoga physician and home practice will be done by patients by watching the video $\mathrm{CD}$ given to them.

The sequence of yoga practices and PMR is illustrated (Table 2 and 3). However, participants have to bring their diary filled regarding the home practice during their visit on every consequent cycle to monitor their treatment compliance.

\begin{tabular}{|c|c|c|c|}
\hline $\begin{array}{l}\text { SI } \\
\text { No }\end{array}$ & Asana & Position & Duration \\
\hline 1. & $\begin{array}{l}\text { Savasana relaxation with breath awareness } \\
\text { (Quick relaxation technique) }\end{array}$ & Supine & 3 minutes \\
\hline 2. & $\begin{array}{l}\text { Uttanapadāsana (Supine straight leg raising, } \\
\text { alternate legs followed by both legs) }\end{array}$ & Supine & 3 minutes \\
\hline 3. & Pavanamuktāsana (Knee chest position) & Supine & 2 minutes \\
\hline 4. & $\begin{array}{l}\text { Savasana - Lying supine while chanting a } \\
\text { monosyllable "A" }\end{array}$ & Prone & 2minutes \\
\hline 5. & Bhujangāsana - Cobra pose & Prone & 2 minutes \\
\hline 6. & Shalabāsana- Locust pose & Prone & 2 minutes \\
\hline 7 & $\begin{array}{l}\text { Makarāsana- Crocodile pose while chanting } \\
\text { monosyllable "U" }\end{array}$ & Prone & 2 minutes \\
\hline 8. & Vajrāsana- & Sitting & 2 minutes \\
\hline 9. & $\begin{array}{l}\text { Shashankāsana- Rabbit pose while chanting } \\
\text { monosyllable "M". }\end{array}$ & Sitting & 2 minutes \\
\hline
\end{tabular}


Citation: Malur R Usharani, PKL Nandini, Raghavendra Rao M, Mahesh Kavya, S Aishvarrya, et al. (2014) Comparison of Yoga vs. Relaxation on Chemotherapy Induced Nausea and Vomiting Outcomes: A Randomized Controlled Trial. J Integr Oncol 3: 116. doi: $10.4172 / 2329-6771.1000116$

Page 6 of 8

\begin{tabular}{|l|l|l|l|}
\hline 10. & $\begin{array}{l}\text { Savasana - Supine rest with breath awareness } \\
\text { and awareness on abdominal and chest } \\
\text { movements (Quick relaxation technique) }\end{array}$ & Supine & 5 minutes \\
\hline
\end{tabular}

Table 2: Sequence of yoga module for intervention (Duration 25minutes)

\begin{tabular}{|c|c|}
\hline Hands & The fists are held tightly (tensed) and relaxed. Then, the fingers are extended and relaxed. \\
\hline Biceps and triceps & $\begin{array}{l}\text { The biceps are tightened such that the fist is not tensed and relaxed. Then the triceps are relaxed by extending the arm and } \\
\text { relaxed. }\end{array}$ \\
\hline Shoulders & The shoulders are pulled backward and relaxed. Likewise, push the shoulders forward making a hunch and relax. \\
\hline Neck (Lateral) & $\begin{array}{l}\text { The shoulders are relaxed and the head is slowly turned towards right side as far as possible and relaxed. Similarly its } \\
\text { turned towards left side and relaxed. }\end{array}$ \\
\hline Neck (forward) & Neck is bent forward such that chin touch into the chest and relaxed. Backward bending of neck is not recommended. \\
\hline Mouth & The mouth is opened as wide as possible and relaxed. The lips are pursed tightly and relaxed. \\
\hline Tongue (extended and retracted) & $\begin{array}{l}\text { Mouth is opened widely and the tongue is extended as far as possible and relaxed on the floor of the mouth. Then the } \\
\text { tongue is retracted slowly inwards into the throat and relaxed. }\end{array}$ \\
\hline Tongue (roof and floor) & $\begin{array}{l}\text { The tongue is extended towards the roof of the mouth touching the palate and relaxed. Similarly the tongue is extended } \\
\text { downward into the bottom of mouth and relaxed. }\end{array}$ \\
\hline Eyes & $\begin{array}{l}\text { The eyes are opened widely making furrows on the brow and relaxed. The eyes are closed tightly and relaxed. } \\
\text { Simultaneously the eyes, forehead and nose are relaxed after each tensing. }\end{array}$ \\
\hline Back & $\begin{array}{l}\text { The body is pushed forward such that the back is arched and relaxed. The shoulder should be relaxed while practicing the } \\
\text { same. One should be cautious while practicing the same. }\end{array}$ \\
\hline Butt & The butt is tensed tightly and pelvis is raised of the floor and relaxed. \\
\hline Thighs & $\begin{array}{l}\text { The legs are raised to about six inches off the floor without tensing the stomach and relaxed. The heels are then pressed } \\
\text { against the floor and relaxed. }\end{array}$ \\
\hline Stomach & The stomach is pulled inward as much as possible and relaxed. Consequently the stomach is pushed outward and relaxed. \\
\hline Calves and feet & $\begin{array}{l}\text { The Feet is extended forwards and relaxed without raising the legs. Feet are pointed upward as far as possible and relaxed. } \\
\text { One needs to be cautious of cramps. (The feet have to be shaken and loosened if cramps are experienced). }\end{array}$ \\
\hline Toes: & Toes are bent forward and relaxed. The toes are bent upward as much as possible and relaxed. \\
\hline
\end{tabular}

Table 3: Sequence of Jacobson's relaxation module for intervention (Duration - 25minutes)

\section{Anti-emetic group only}

Participants in this group will be only on anti-emetics and will be guided about their diet and nutrition which is usually recommended in the hospital as a routine standard of care. Participants fear about chemotherapy and concerns will be allayed through education interventions normally followed for all patients in the hospital as a standard of care.

\section{Chemotherapy regimen}

All subjects in this study will receive a moderately emetogenic chemotherapy schedule during the course of their chemotherapy following NCCN Guidelines [2]. The chemotherapy schedule will be fixed for all the patients as heterogeneity in drug combinations can affect CINV outcomes.

\section{Class Site}

Both yoga and Jacobson exercise will be taught individually in a well-ventilated, quiet room, within hospital premises. Props will be used for those who find it difficult to do the exercise.

\section{Instructors training and monitoring}

Certified Yoga instructors with more than 200 hours of training will be recruited to undergo training in integrative oncology department to comprehend psycho oncology issues and clinical issues related to cancer patients. They will be required to put in a minimum of $100 \mathrm{hrs}$ of teaching cancer patients before they train participants in the research study. The instructors have to strictly adhere to treatment protocol which will be closely monitored by the PI and Research coordinators. Since all participants will not be able to understand English, preference will be given to instructors who know more languages. 
Citation: Malur R Usharani, PKL Nandini, Raghavendra Rao M, Mahesh Kavya, S Aishvarrya, et al. (2014) Comparison of Yoga vs. Relaxation on Chemotherapy Induced Nausea and Vomiting Outcomes: A Randomized Controlled Trial. J Integr Oncol 3: 116. doi: $10.4172 / 2329-6771.1000116$

Page 7 of 8

\section{Data collection and quality control}

NV episodes, quality of life and psychological states will be analyzed using self-report questionnaires filled by participants. The data entry and scoring will be done by personnel not involved in the study and not having knowledge of the allocation. Neurophysiological data will be recorded using the same instrument under similar rest conditions for all participants. These data will be blinded and interpreted neurophysiologists in a collaborating institute.

\section{Protection of human subjects and assessment of safety}

This study has been approved by the institutional review board or ethics committee, constituted as per Schedule Y and ICMR guidelines. Written consent will be obtained from all subjects before participating in this study.

Patients will be asked to perform the practices slowly and gently to avoid any musculoskeletal injuries. In case any participant develops any musculoskeletal injury she/he will be asked to stop the practice and referred to Orthopedics and physiotherapy departments for care. Such adverse events will be documented and patients can resume intervention only after resolution of their complaints. Safety of participants will be monitored by the oncologists. In case frequent adverse events are encountered audit will be done and the report presented to ethics committee for suitable action.

\section{Adverse events}

Cancer patients will be monitored for toxicity due to chemotherapy and musculoskeletal injuries resulting from yoga practices using CTC. Study will be stopped temporarily for any participant developing grade IV toxicity and continued after resolution of the same. All adverse events during the study period will be documented using the Common Toxicity Criteria Version 3 [48].

\section{Stopping rules}

Study stoppage rules apply in case the patient is noncompliant to intervention, has undue toxicity or injury that limits adherence to intervention or if he/ she develops progressive disease during the chemotherapy treatment.

\section{Statistical analysis}

\section{Data analysis}

Data will be analyzed using Statistical package for Social Sciences Version 18.

\section{Primary analysis}

The primary analysis involves analysis of NV episode frequency and severity and their impact on quality of life at subsequent cycles of chemotherapy. We will use a Repeated measures ANOVA with post Hoc Bonferroni correction to analyze difference between groups at follow-up intervals wherein $95 \%$ CI for $p$ value is fixed at $(\mathrm{p}=0.02)$. The data will be analyzed using intention to treat approach accounting for missing values using appropriate statistical imputation methods. Similarly analysis for secondary outcomes such as perceived stress, State anxiety, depression scores, LF/HF ratio, and HRV analysis, frequency of bradygastria / normogastria and tachygastria in subsequent cycles will be analyzed using the above methodology.

\section{Secondary analysis}

Secondary analysis will determine bi-variate relationships between psychological variables such as perceived stress, depression, anxiety and changes in cardiac autonomic function and EGG using correlation and linear regression models.

\section{Conclusion}

This study will help us understand the mechanism of action of yoga intervention in controlling CINV identify predictors for managing CINV.

\section{Ethical Approval}

HCG Central ethics committee has approved the study whose IRB number is Y010810.

\section{Funding}

This study is funded with grants from Central Council for Research in Yoga and Naturopathy, Dept of AYUSH, Ministry of Health and Family Welfare, Govt of India with Dr Raghavendra Rao M as PI.

\section{References}

1. Hesketh PJ (2008) Chemotherapy-induced nausea and vomiting. N Engl J Med 358: 2482-2494.

2. National Comprehensive Cancer Network (NCCN) Antiemesis. NCCN Guidelines 2011

3. Roscoe JA, Morrow GR, Hickok JT, Stern RM (2000) Nausea and vomiting remain a significant clinical problem: trends over time in controlling chemotherapy-induced nausea and vomiting in 1413 patients treated in community clinical practices. J Pain Symptom Manage 20: 113-121.

4. Grunberg SM, Deuson RR, Mavros P, Geling O, Hansen M, et al. (2004) Incidence of chemotherapy-induced nausea and emesis after modern antiemetics. Cancer 100: 2261-2268.

5. Grunberg SM, Slusher B, Rugo HS (2013) Emerging treatments in chemotherapy-induced nausea and vomiting. Clin Adv Hematol Oncol 11: 1-18.

6. Navari RM, Nagy CK, Gray SE (2013) The use of olanzapine versus metoclopramide for the treatment of breakthrough chemotherapyinduced nausea and vomiting in patients receiving highly emetogenic chemotherapy. Supportive Care in Cancer 21: 1655-1663.

7. Koeller JM, Matti SA, Richard JG, Steven MG, Clark-Snow, et al. (2002) Antiemetic guidelines: creating a more practical treatment approach. Support Care Cancer 10: 519-522.

8. Cohen L, de Moor CA, Eisenberg P, Ming EE, Hu H (2007) Chemotherapy-induced nausea and vomiting: incidence and impact on patient quality of life at community oncology settings. Support Care Cancer 15: 497-503.

9. Glaus A, Knipping C, Morant R, Böhme C, Lebert B, et al. (2004) Chemotherapy-induced nausea and vomiting in routine practice: a European perspective. Support Care Cancer 12: 708-715.

10. Bonadonna G, Valagussa P, Moliterni A, Zambetti M, Brambilla C (1995) Adjuvant cyclophosphamide, methotrexate, and fluorouracil in nodepositive breast cancer: the results of 20 years of follow-up. N Engl J Med 332: 901-906.

11. Bosly A, Bron D, Van Hoof A, De Bock R, Berneman Z, et al. (2008) Achievement of optimal average relative dose intensity and correlation with survival in diffuse large B-cell lymphoma patients treated with CHOP. Ann Hematol 87: 277-283.

12. Young A, Crowe M, Vidall C, Lennan E, Roe H, et al. (2009) Delivery of chemotherapy at planned dose and on time. Cancer Nurs Pract 8: 16-19. 
Citation: Malur R Usharani, PKL Nandini, Raghavendra Rao M, Mahesh Kavya, S Aishvarrya, et al. (2014) Comparison of Yoga vs. Relaxation on Chemotherapy Induced Nausea and Vomiting Outcomes: A Randomized Controlled Trial. J Integr Oncol 3: 116. doi: $10.4172 / 2329-6771.1000116$

Page 8 of 8

13. Vidall C, Dielenseger P, Farrell C, Lennan E, Muxagata P, et al. (2011) Evidence-based management of chemotherapy-induced nausea and vomiting: a position statement from a European cancer nursing forum. Ecancermedicalscience 5: 211.

14. Molassiotis A, Yung HP, Yam BM, Chan FY, MokT (2002) The effectiveness of progressive muscle relaxation training in managing chemotherapy-induced nausea and vomiting in Chinese breast cancer patients: a randomised controlled trial. Support Care Cancer 10: 237-246.

15. De WR, Herrstedt J, Rapoport B, Carides AD, Guoguang-Ma J, et al. (2004) The oral NK(1) antagonist, aprepitant, given with standard antiemetics provides protection against nausea and vomiting over multiple cycles of cisplatin-based chemotherapy: a combined analysis of two randomised, placebo-controlled phase III clinical trials. Eur J Cancer 40: 403-410.

16. Kramer MS, Winokur A, Kelsey J, Preskorn SH, Rothschild AJ, et al. (2004) Demonstration of the efficacy and safety of a novel substance P (NK1) receptor antagonist in major depression. Neuropsychopharmacology 29: 385-392.

17. Rupniak NM (2002) New insights into the antidepressant actions of substance P (NK1 receptor) antagonists. Can J Physiol Pharmacol 80: 489-494.

18. Orita K, Hiramoto K, Inoue R, Sato EF, Kobayashi H, et al. (2010) Strong exercise stress exacerbates dermatitis in atopic model mice, $\mathrm{NC} / \mathrm{Nga}$ mice, while proper exercise reduces it. Exp Dermatol 19: 1067-1072.

19. Molassiotis A (2000) A pilot study of the use of progressive muscle relaxation training in the management of post-chemotherapy nausea and vomiting. Eur J Cancer Care (Engl) 9: 230-234.

20. Taneja I, Deepak KK, Poojary G, Acharya IN, Pandey RM, et al. (2004) Yogic versus conventional treatment in diarrhea-predominant irritable bowel syndrome: a randomized control study. Appl Psychophysiol Biofeedback 29: 19-33.

21. Abell TL, Van Cutsem E, Abrahamsson H, Huizinga JD, Konturek JW, et al. (2002) Gastric electrical stimulation in intractable symptomatic gastroparesis. Digestion 66: 204-212.

22. Kvale G, Hugdahl K, Asbjørnsen A, Rosengren B, Lote K, et al. (1991) Anticipatory nausea and vomiting in cancer patients. J Consult Clin Psychol 59: 894-898.

23. Schwartz MD, Jacobsen PB, Bovbjerg DH (1996) Role of nausea in the development of aversions to a beverage paired with chemotherapy treatment in cancer patients. Physiol Behav 59: 659-663.

24. Rao RM, Telles S, Nagendra HR, Nagarathna R, Gopinath K, et al. (2008) Effects of yoga on natural killer cell counts in early breast cancer patients undergoing conventional treatment. Comment to: recreational musicmaking modulates natural killer cell activity, cytokines, and mood states in corporate employees Masatada W, Masahiro K, Masanori U, Barry BB, Masanobu K, Katsuiku Hirokawa Med Sci Monit, 2007; 13 (2): CR57-70. Med Sci Monit 14: 3-4.

25. Vadiraja HS, Rao MR, Nagarathna R, Nagendra HR, Rekha M, et al. (2009) Effects of yoga program on quality of life and affect in early breast cancer patients undergoing adjuvant radiotherapy: a randomized controlled trial. Int J Yoga 2: 73-79.

26. Rao MR, Raghuram N, Nagendra HR, Gopinath KS, Srinath BS, et al. (2009) Anxiolytic effects of a yoga program in early breast cancer patients undergoing conventional treatment: a randomized controlled trial. Complement Ther Med 17: 1-8.

27. Cohen L, Warneke C, Fouladi RT, Rodriguez MA, Chaoul-Reich A (2004) Psychological adjustment and sleep quality in a randomized trial of the effects of a Tibetan yoga intervention in patients with lymphoma. Cancer 100: 2253-2260.

28. Raghavendra RM, Nagarathna R, Nagendra HR, Gopinath KS, Srinath $\mathrm{BS}$, et al. (2007) Effects of an integrated yoga programme on chemotherapy-induced nausea and emesis in breast cancer patients. Eur J Cancer Care (Engl) 16: 462-474.

29. Buffart LM, van Uffelen JG, Riphagen II, Brug J, van Mechelen W, et al (2012) Physical and psychosocial benefits of yoga in cancer patients and survivors, a systematic review and meta-analysis of randomized controlled trials. BMC Cancer 12: 559.

30. Harder H, Parlour L, Jenkins V (2012) Randomised controlled trials of yoga interventions for women with breast cancer: a systematic literature review. Support Care Cancer 20: 3055-3064.

31. Zhang J, Yang KH, Tian JH, Wang CM (2012) Effects of yoga on psychologic function and quality of life in women with breast cancer: a meta-analysis of randomized controlled trials. J Altern Complement Med 18: 994-1002.

32. White P, White S, Edmonds P, Gysels M, Moxham J, et al. (2011) Palliative care or end-of-life care in advanced chronic obstructive pulmonary disease: a prospective community survey. Br J Gen Pract 61: e362-370.

33. Whitley E, Ball J (2002) Statistics review 4: sample size calculations. Crit Care 6: 335-341.

34. Martin AR, Pearson JD, Cai B, Elmer M, Horgan K, et al. (2003) Assessing the impact of chemotherapy-induced nausea and vomiting on patients' daily lives: a modified version of the Functional Living IndexEmesis (FLIE) with 5-day recall. Support Care Cancer 11: 522-527.

35. Cohen S1, Williamson GM (1991) Stress and infectious disease in humans. Psychol Bull 109: 5-24.

36. Zigmond AS, Snaith RP (1983) The hospital anxiety and depression scale. Acta Psychiatr Scand 67: 361-370.

37. Bjelland I, Dahl AA, Haug TT, Neckelmann D (2002) The validity of the Hospital Anxiety and Depression Scale. An updated literature review. J Psychosom Res 52: 69-77.

38. Park MJ, Green J, Ishikawa H, Yamazaki Y, Kitagawa A, et al. (2013) Decay of impact after self-management education for people with chronic illnesses: changes in anxiety and depression over one year. PLoS One 8: e65316.

39. Parkman HP, Hasler WL, Barnett JL, Eaker EY; American Motility Society Clinical GI Motility Testing Task Force (2003) Electrogastrography: a document prepared by the gastric section of the American Motility Society Clinical GI Motility Testing Task Force. Neurogastroenterol Motil 15: 89-102.

40. You CH, Lee KY, Chey WY, Menguy R (1980) Electrogastrographic study of patients with unexplained nausea, bloating, and vomiting. Gastroenterology 79: 311-314.

41. Yoo SH, Yun YH, Park S, Kim YA, Park SY, et al. (2013) The correlates of unemployment and its association with quality of life in cervical cancer survivors. J Gynecol Oncol 24: 367-375.

42. Aasprang A, Andersen JR, Våge V, Kolotkin RL, Natvig GK (2013) Fiveyear changes in health-related quality of life after biliopancreatic diversion with duodenal switch. Obes Surg 23: 1662-1668.

43. Basch E, Prestrud AA, Hesketh PJ, Kris MG, Feyer PC, et al. (2011) Antiemetics: American Society of Clinical Oncology clinical practice guideline update. J Clin Oncol 29: 4189-4198.

44. Buntrock C, Ebert DD, Lehr D, Cuijpers P, Riper H, et al. (2014) Evaluating the efficacy and cost-effectiveness of web-based indicated prevention of major depression: design of a randomised controlled trial. BMC Psychiatry 14: 25.

45. Borison HL, McCarthy LE (1983) Neuropharmacology of chemotherapyinduced emesis. Drugs 25 Suppl 1: 8-17.

46. Saraswati SS, Hiti JK (1996) Asana pranayama mudra bandha. (1st Edn.), Bihar Yoga Bharati. Bihar, India.

47. Vempati RP, Telles S (2002) Yoga-based guided relaxation reduces sympathetic activity judged from baseline levels. Psychol Rep 90: 487-494.

48. Trotti A, Colevas AD, Setser A, Rusch V, Jaques D, et al. (2003) CTCAE v3.0: development of a comprehensive grading system for the adverse effects of cancer treatment. Semin Radiat Oncol 13: 176-181. 